\title{
Thyroid Gland Papillary Carcinoma with
} Fibromatosis/Fasciitis-Like Stroma

National Cancer Institute

\section{Source}

National Cancer Institute. Thyroid Gland Papillary Carcinoma with Fibromatosis/Fasciitis-

Like Stroma. NCI Thesaurus. Code C126410.

A rare morphologic variant of papillary thyroid gland carcinoma characterized by the presence of abundant and cellular stroma resembling nodular fasciitis, fibromatosis, or other proliferative myofibroblastic processes. (WHO 2017) 